\title{
DEBULHADOR MANUAL DE MILHO VERDE PARA A AGRICULTURA FAMILIAR
}

\author{
Tiago Vega Custódio ${ }^{1}$, Marina Peter Schwab ${ }^{2}$, Maria Eduarda Silveira dos Anjos ${ }^{2}$, Roberto Lilles Tavares Machado ${ }^{2}$, Antônio Lilles \\ Tavares Machado ${ }^{2}$ \\ 1 Programa de Pós-Graduação em Sistemas de Produção Agrícola Familiar, Universidade Federal de Pelotas, 96010-610, Pelotas, \\ Brasil. \\ ${ }^{2}$ Departamento de Engenharia Rural da Faculdade de Agronomia, Universidade Federal de Pelotas, 96010-610, Pelotas, Brasil.
}

*E-mail: tiagovegacustodio@gmail.com

\section{RESUMO}

Nas propriedades familiares vem crescendo a implantação de pequenas agroindústrias de processamento de produtos oriundos do próprio setor. O milho verde em conserva é um exemplo de produto comercializado pelos produtores familiares, porém, necessita ser debulhado, sendo essa tarefa normalmente executada de forma manual com auxílio de ferramentas domésticas. Os debulhadores de milho verde comercializados atualmente são para produção em alta escala, tornando-se equipamentos inacessíveis aos agricultores familiares. Nesse contexto, este estudo teve a finalidade de desenvolver um debulhador de milho verde para esses produtores. A metodologia utilizada fundamenta-se no Modelo de Fases, empregado com êxito no projeto de máquinas agrícolas, o qual se divide em quatro etapas: projeto informacional, projeto conceitual, projeto preliminar e projeto detalhado. Como resultado da aplicação da metodologia, obtiveram-se três concepções e três protótipos de debulhadores de milho verde. Após a realização dos ensaios, o protótipo 3 foi determinado o ideal para atender às necessidades dos agricultores familiares.

Palavras-chave: Máquinas agrícolas. Desenvolvimento de produto.

\section{Introdução}

O Brasil é atualmente o terceiro maior produtor de milho do mundo. No censo agropecuário de 2017 foram identificadas 1.628.805 propriedades produtoras de milho, contando com uma produção de $90.822 .585,448$ de toneladas [1]. A projeção é que a produção aumente, visto que a estimativa para a safra 2018/2019 é em torno de 97 milhões de toneladas [2].

O milho (Zea mays L.) pode ser comercializado de diversas formas, tanto para consumo humano quanto para consumo animal; no Brasil há ascendência na comercialização do milho verde [34].

A produção de milho verde possui importante contribuição para a geração de empregos e utiliza principalmente a mão de obra familiar para a sua produção e beneficiamento [5].

O milho verde apresenta uma grande diversificação no mercado, permitindo a comercialização dos grãos in natura, cozidos ou como ingredientes de diversos alimentos [6]. Embora a produção de milho em grãos seja bastante comum, o milho verde possui maior valor de mercado, proporcionando uma receita complementar ao agricultor [7].

O milho verde é geralmente colhido com os grãos no estádio leitoso, entre 20 a 25 dias após a emissão dos estiletes (cabelos), quando as espigas apresentam estiletes de cor castanhoclara. Espigas com grãos imaturos na ponta tendem a possuir melhor qualidade em relação àquelas em que todos os grãos já atingiram o tamanho máximo [8].

Para maior rendimento na operação da debulha do milho verde é necessário que a espiga possua determinadas características de diâmetro, comprimento e profundidade dos grãos [9], sendo recomendados debulhadores manuais ou com baixa rotação para essa operação [10].

No entanto, existem poucos equipamentos no comércio adequados às características dos produtores familiares, visto que 
muitos desses equipamentos são caros e apresentam capacidade de produção muito superior às necessidades dos agricultores familiares [11-12].

Dessa forma, o objetivo do trabalho foi projetar e confeccionar um debulhador manual de milho verde que atendesse às necessidades dos agricultores familiares.

\section{Metodologia}

O desenvolvimento do debulhador manual de milho verde foi realizado no Núcleo de Inovação em Máquinas e Equipamentos Agrícolas (NIMEq) da Faculdade de Agronomia Eliseu Maciel (FAEM) da Universidade Federal de Pelotas (UFPel). A metodologia utilizada fundamenta-se no Modelo de Fases, o qual é utilizado com êxito na geração de produtos como, por exemplo, para a obtenção da estrutura funcional de uma semeadora de acionamento manual [13], na determinação de uma estrutura funcional de um encanteirador e depositor de fertilizantes para tratores de baixa potência [14], na determinação de especificações para o projeto de um mecanismo aplicador de calor [15] e no projeto conceitual de máquina para o controle de plantas daninhas pela aplicação de calor [16].

O modelo de fases é dividido em quatro etapas: projeto informacional, projeto conceitual, projeto preliminar e projeto detalhado [14]. Ao fim de cada etapa, obtêm-se, como resultados, as especificações do projeto, a concepção do produto, o leiaute definitivo e a documentação do produto, sendo que neste trabalho executaram-se algumas tarefas dos projetos informacional e conceitual, porém, necessitou-se adaptá-las ao projeto de acordo com as necessidades que surgiram durante o desenvolvimento, pois cada projeto tem o seu problema característico.

O ponto de partida para o presente trabalho foram visitas realizadas em propriedades familiares com a finalidade de pesquisar as necessidades em relação à mecanização agrícola, no sentido de buscar e desenvolver soluções para atender essas carências.

Após a identificação das necessidades dos clientes, iniciouse a transformação das necessidades em requisitos dos deles, por meio da conversão das necessidades descritas em linguagem informal em uma linguagem de engenharia, mais compacta e apropriada ao entendimento da equipe de projeto.

Em seguida foram gerados os princípios de solução para o desenvolvimento dos Sistemas, Subsistemas e Componentes (SSCs) das concepções do debulhador manual de milho verde; essa tarefa de projeto foi realizada por meio de pesquisa bibliográfica, análise de sistemas técnicos existentes e do método intuitivo de brainstorming, porém, sem limite de tempo para que cada membro da equipe de projeto sugerisse suas ideias de maneira clara e completa, segundo critérios técnicos e econômicos. Após a geração dos princípios de solução foi determinada a função global do produto.

Posteriormente foi realizada a análise e modelagem dos diferentes princípios de solução por meio de um programa CAD (do inglês Computer-Aided Design), servindo de apoio para a elaboração de uma matriz morfológica, ampliando as possibilidades de combinações e recombinações dos princípios de solução. Esse método facilita a comunicação entre os membros do projeto por meio da visualização das montagens e dos princípios de solução [17].

As concepções originadas pelos princípios de solução foram detalhadas, dimensionadas e seus respectivos protótipos foram fabricados segundo as recomendações [18-19]. Após a execução dos equipamentos, eles foram testados quanto à facilidade e à agilidade na operação de debulha, segurança dos operadores e valor de fabricação. No entanto, antes da fabricação dos protótipos as concepções foram avaliadas por meio da matriz de avaliação das concepções ou método de Pugh, que se recomenda para a seleção do produto mais promissor [19], utilizando-se os requisitos de cliente como critérios de avaliação conforme utilizado por Oldoni [20].

\section{Resultados e discussões}

Na Tabela 1 é apresentada a distribuição de frequência dos valores de importância obtidos no diagrama de Mudge em dez classes, que foram obtidas pela inserção dos dados em um histograma de frequência com amplitude variando de 0 a 18,83, sendo que a primeira classe apresentou intervalo de 0 a 1,88 e a última, de 16,95 a 18,83.

O requisito de cliente mais importante, após aplicação da ferramenta diagrama de Mudge, foi debulhar a espiga de milho $(14,42 \%)$, que é a função do equipamento; resultados semelhantes foram alcançados por Oldoni [20], o qual verificou que as funções da máquina obtiveram maior valoração que os demais.

O requisito de cliente menos importante foi ter baixa massa $(0 \%)$; este, ao ser mantido com os demais para a classificação por meio do histograma de frequência, permaneceu na classe 1 , da mesma forma que os demais valores não nulos dessa classe.

A tarefa seguinte foi a determinação da função global do produto, que é debulhar uniformemente os grãos de milho verde, em que a palavra "debulhar" refere-se à retirada manual apenas dos grãos maduros, com a exceção dos grãos imaturos na ponta, pois não apresentam a qualidade nem o formato uniforme desejado para a comercialização. 


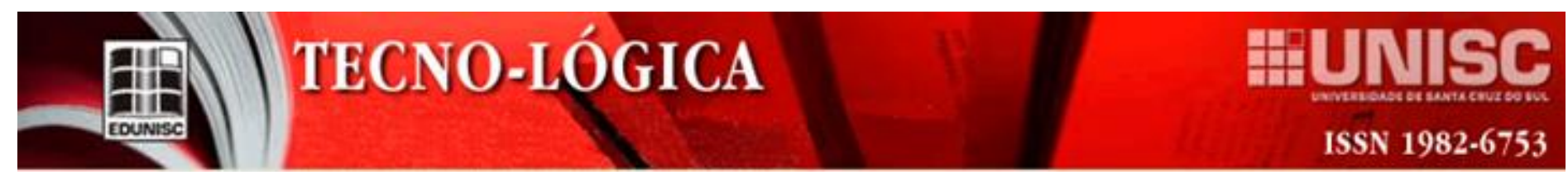

Tabela 1 - Hierarquização dos requisitos de clientes.

\begin{tabular}{lcc}
\hline Requisitos de clientes & Classe & Hierarquização (\%) \\
\hline Debulhar a espiga de milho & 10 & 18,83 \\
Cortar os grãos uniformemente & 10 & 18,41 \\
Ser fácil de operar & 9 & 15,89 \\
Ter baixo esforço de operação & 8 & 14,23 \\
Ter baixo custo & 8 & 14,23 \\
Ser segura & 3 & 4,6 \\
Ter durabilidade & 3 & 4,18 \\
Ser ergonômica & 2 & 3,35 \\
Ter manutenção fácil & 2 & 2,09 \\
Ter peças padronizadas & 1 & 1,26 \\
Ter pouca manutenção & 1 & 1,26 \\
Ser fácil de regular & 1 & 1,25 \\
Ser fácil de montar & 1 & 0,42 \\
Ter baixa massa & 1 & 0 \\
\hline
\end{tabular}

Com a utilização do método da matriz morfológica e com a combinação dos princípios de solução foi possível a confecção de três concepções e seus protótipos.

Na concepção 1, apresentada na Figura 1, o sistema de corte dos grãos da espiga de milho é constituído de uma lâmina circular, a qual possibilita o corte dos grãos em espigas de diâmetros variados. A base fabricada de aço carbono possui uma pequena depressão na área de contato com a espiga, dessa forma torna-se possível equilibrar a espiga quando o equipamento estiver funcionando.

A base apresenta duas hastes que possibilitam o deslizamento dos punhos, permitindo uma debulha mais homogênea da espiga. Os punhos confeccionados em aço carbono têm a função de sustentar as mãos do operador e ajustar a lâmina em relação ao diâmetro da espiga.

O funcionamento do equipamento se dá por meio do posicionamento da espiga sobre a base de fixação; em seguida a lâmina circular atua sobre a espiga, deslocando-se no sentido vertical para baixo, efetuando a operação de debulha.

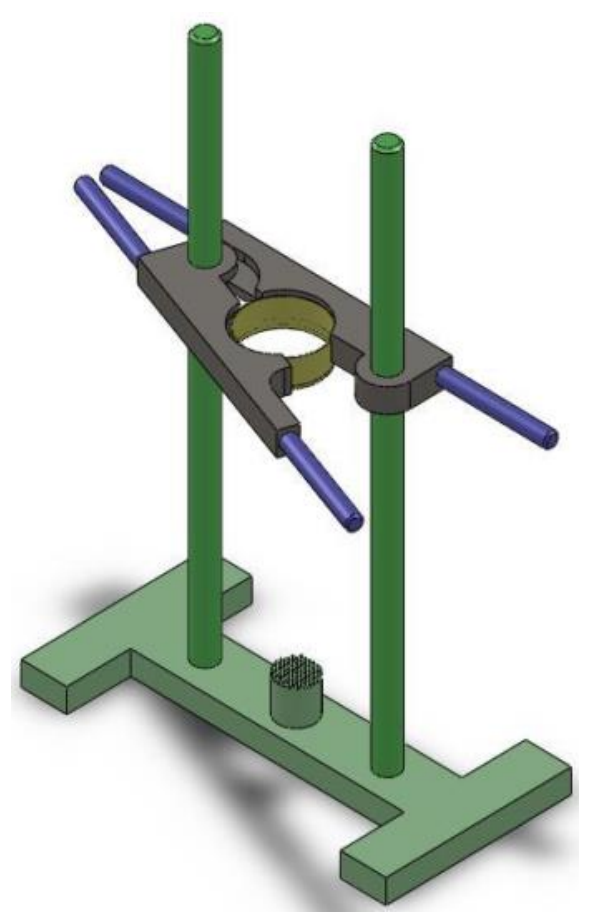

Figura 1 - Representação gráfica tridimensional do debulhador manual de milho verde - concepção 1 .

Na concepção 2 (Figura 2), o sistema de corte é formado de uma lâmina circular, fixada na base do equipamento; por conta de suas dimensões, as operações de debulha e o descarte do sabugo são simultâneas. A base apresenta ainda duas hastes para fixação da alavanca e outras duas com função de possibilitar o deslocamento da espiga.

O funcionamento do debulhador manual é realizado com a espiga posicionada na parte superior; com o auxílio de uma alavanca a espiga de milho é deslocada de cima para baixo até que passe por inteira pelo o sistema de corte, permitindo a separação dos grãos e do sabugo de forma rápida, precisa e segura.

O protótipo 2 foi construído de aço carbono, no entanto, o produto final deverá ser de aço inoxidável e poliamida 6 , pois são materiais de fácil higienização, não transferem sabor ou odor ao alimento e são resistentes à corrosão. Equipamentos que entram em contato com os alimentos devem apresentar materiais que não transmitem substâncias tóxicas, odores nem sabores aos alimentos [21]. 

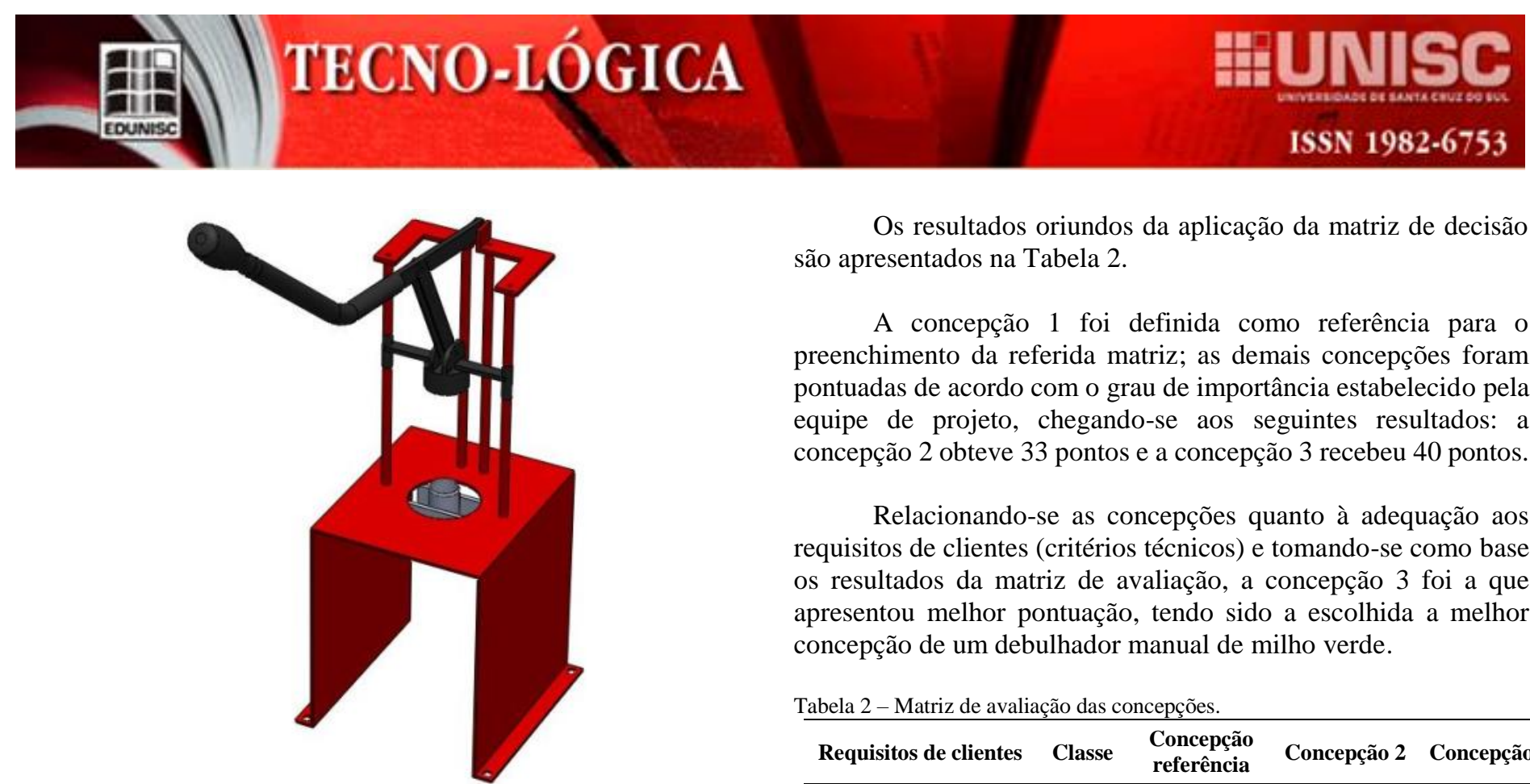

Os resultados oriundos da aplicação da matriz de decisão são apresentados na Tabela 2.

A concepção 1 foi definida como referência para o preenchimento da referida matriz; as demais concepções foram pontuadas de acordo com o grau de importância estabelecido pela equipe de projeto, chegando-se aos seguintes resultados: a concepção 2 obteve 33 pontos e a concepção 3 recebeu 40 pontos.

Relacionando-se as concepções quanto à adequação aos requisitos de clientes (critérios técnicos) e tomando-se como base os resultados da matriz de avaliação, a concepção 3 foi a que apresentou melhor pontuação, tendo sido a escolhida a melhor concepção de um debulhador manual de milho verde.

Tabela 2 - Matriz de avaliação das concepções.

Figura 2 - Representação gráfica tridimensional do debulhador manual de milho verde - concepção 2 .

A concepção 3 (Figura 3) apresenta o funcionamento semelhante ao da concepção 2 ; a espiga de milho é fixada na parte superior do equipamento e pelo movimento da alavanca a espiga é deslocada até a lâmina.

As operações de debulha e o descarte do sabugo também são simultâneas. No entanto, as guias que permitem o movimento da alavanca não são mais anéis de aço carbono (Figura 2); na concepção 3 são roletes de poliamida 6 , sendo quatro roletes para cada haste de apoio da alavanca.

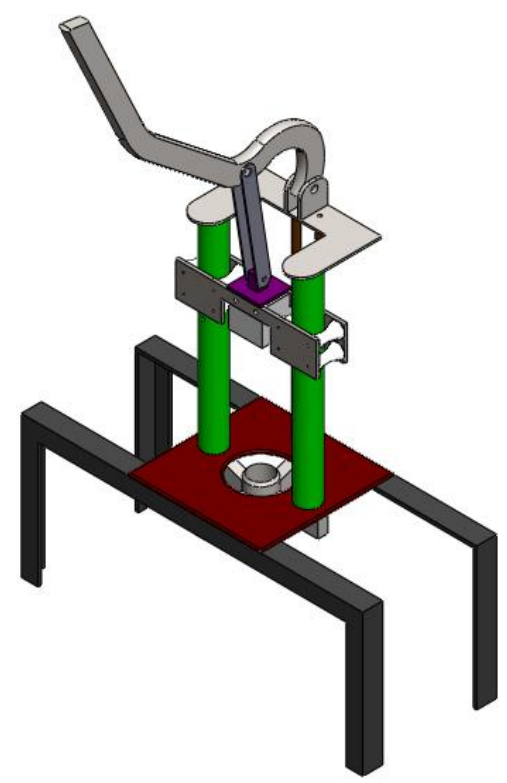

Figura 3 - Representação gráfica tridimensional do debulhador manual de milho verde - concepção 3 .

\begin{tabular}{lcccc}
\hline Requisitos de clientes & Classe & $\begin{array}{c}\text { Concepção } \\
\text { referência }\end{array}$ & Concepção 2 & Concepção 3 \\
\hline $\begin{array}{l}\text { Debulhar a espiga de } \\
\text { milho }\end{array}$ & 10 & 0 & 1 & 1 \\
$\begin{array}{l}\text { Cortar os grãos } \\
\text { uniformemente }\end{array}$ & 10 & 0 & 1 & 0 \\
Ser fácil de operar & 9 & 0 & 0 & -1 \\
Ter baixo esforço de & 8 & 0 & 0 & 0 \\
operação & 8 & 0 & 0 & 0 \\
Ter baixo custo & 3 & 0 & 2 & -1 \\
Ser segura & 3 & 0 & 0 & 0 \\
Ter durabilidade & 2 & 0 & 1 & 1 \\
Ser ergonômica & 2 & 0 & 1 & 0 \\
Ter manutenção fácil & 1 & 0 & -1 & 0 \\
Ter peças padronizadas & 1 & 0 & 1 & 0 \\
Ter pouca manutenção & 1 & 0 & 0 & 1 \\
Ser fácil de regular & 1 & 0 & 1 & 0 \\
Ser fácil de montar & 1 & 0 & 0 & 0 \\
Ter baixa massa & 1 & & &
\end{tabular}

Por meio dos testes, constatou-se que o protótipo 1 (Figura 4) necessita de grande esforço do operador para realização da debulha, possibilitando pouca segurança ao operador no momento da operação. O sistema de lâmina que permite regulagens se comportou de forma ineficiente quando pressionado, deformandose e passando de um formato circular para um formato elíptico, dessa forma realizando um corte irregular.

O custo de aquisição, o qual é uma necessidade de grande importância para o agricultor familiar [15,22-23] depende do custo de fabricação; para a confecção do protótipo $1 \mathrm{o}$ valor total foi de $\mathrm{R} \$ 96,50$, sendo $\mathrm{R} \$ 6,50 \mathrm{com}$ materiais e o restante com serviços de usinagem. 


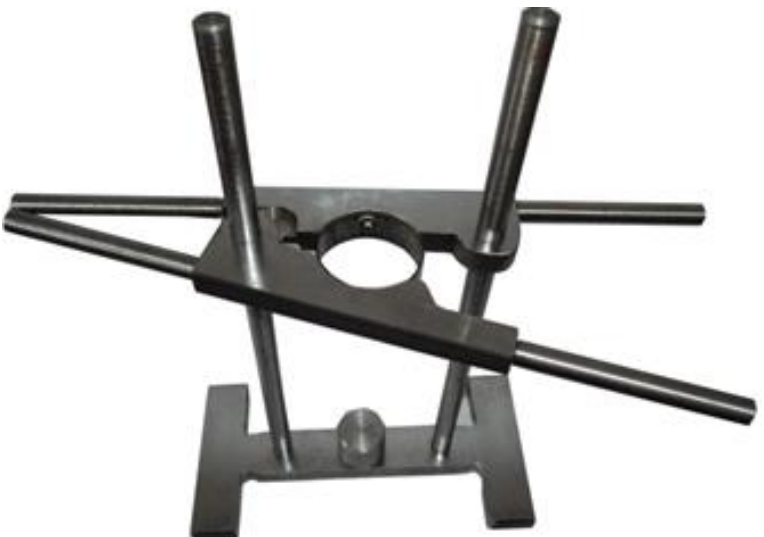

Figura 4 - Protótipo 1 do debulhador manual de milho verde.

Ao testar o protótipo 2 (Figura 5), constatou-se que a manutenção do formato circular do sistema cortador permitiu um corte regular ao longo da espiga separando os grãos do sabugo uniformemente, deixando-os inteiros; apenas os grãos imaturos da ponta da espiga não foram debulhados, porém, esses grãos são considerados defeituosos para Instrução Normativa [24].

Outra vantagem em relação ao protótipo 1 foi a necessidade de menor esforço do operador ao realizar a debulha devido à maior dimensão e ao ângulo da alavanca; no entanto, quando a lâmina estava no meio do percurso havia a necessidade de maior esforço pelo operador, por conta da inclinação dos anéis em relação às hastes, assim proporcionando atrito entre esses elementos.

Com relação aos custos de fabricação, para a confecção do protótipo 1 gastou-se um total de $\mathrm{R} \$ 220,00$, sendo $\mathrm{R} \$ 20,00$ com materiais e $\mathrm{R} \$ 200,00$ com serviços de usinagem.

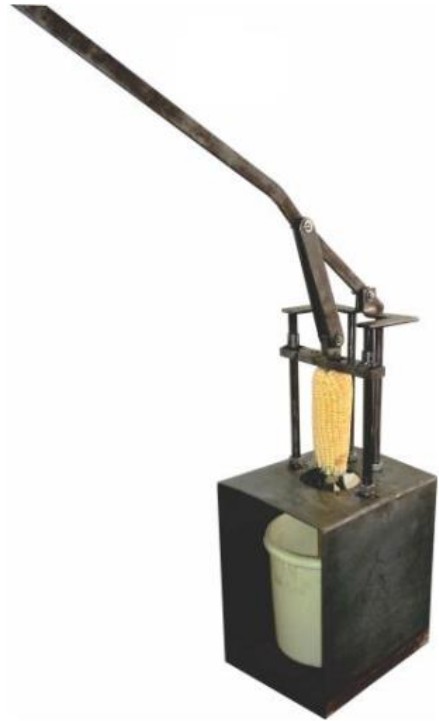

Figura 5 - Protótipo 2 do debulhador manual de milho verde.
O protótipo 3 (Figura 6), originado da concepção 3, foi otimizado durante o seu desenvolvimento, pois nos testes realizados no protótipo 2 foi identificado um desconforto do operador quanto ao posicionamento da mão na alavanca para mover a espiga de milho; devido a esse fato foi inserido um punho na ponta da alavanca que serve de suporte para a mão do operador.

Outra mudança realizada na alavanca em relação à concepção foi a mudança no ângulo, visto que nos testes do protótipo 2 não foi esse o problema que causou maior esforço do operador.

Para resolver o defeito do atrito dos anéis com as hastes, os anéis foram substituídos por roletes fabricados com poliamida 6 , pois esse material apresenta características como boa rigidez e tenacidade e é inerte a quase todos os tipos de óleos e solventes existentes [25], além de possuir baixo coeficiente de atrito e ser autolubrificante [26].

O custo de fabricação do equipamento foi a característica mais solicitada [14] de um equipamento agrícola em entrevistas realizadas com agricultores familiares. No protótipo 3 , esse valor foi de 250,00, em que $\mathrm{R} \$ 42,00$ foram gastos com material e o restante com os serviços de usinagem do protótipo.

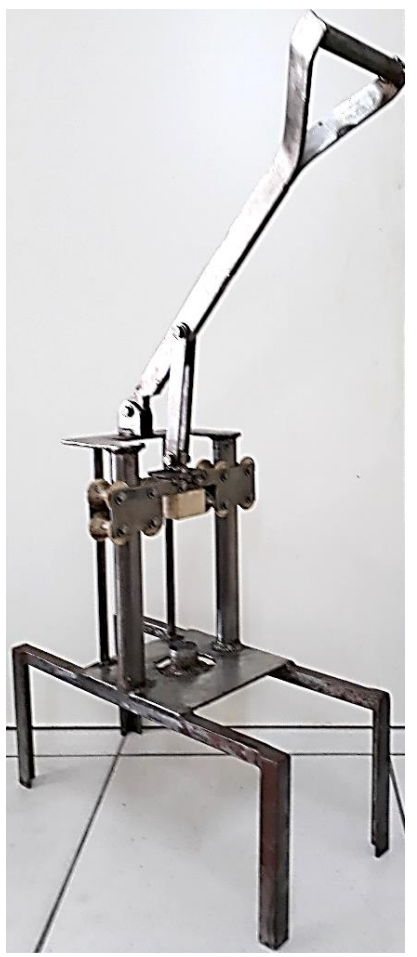

Figura 6 - Protótipo 3 do debulhador manual de milho verde. 
Embora os valores gastos com materiais para a fabricação dos três protótipos tenham sido relativamente baixos, apenas alguns materiais empregados são de inox, que é um dos materiais recomendado pela legislação [21].

Os serviços de usinagem e a compra de material em pequena escala tornaram a elaboração dos protótipos mais onerosa, no entanto, a produção em maior escala e em uma empresa diminuiria o custo dos equipamentos.

Por meio dos testes com o debulhador de milho verde, constatou-se que o terceiro protótipo demonstrou maior eficiência na operação de debulha e apresentou menor risco à segurança do operador, necessitando apenas de uma fonte de energia humana, e permite a retirada total dos grãos da espiga sem perdas e diminui a possibilidade de acidentes, o que ocorre no método tradicional, que vem a ser a utilização de uma faca, sendo determinado por meio de testes o protótipo 3 como o mais adequado para a necessidade do agricultor familiar.

O emprego desse equipamento na agricultura familiar é uma solução simples, segura e eficiente para a operação de debulha de milho verde para conserva, pois a debulha deve ser manual ou com um debulhador de baixa rotação para evitar danos mecânicos [10].

\section{Conclusões}

Foi possível, com a utilização da metodologia de projeto sistematizada, a construção de três concepções de debulhadores manuais de milho verde e seus respectivos protótipos.

O protótipo 3 do debulhador manual de milho verde demonstrou maior eficiência na operação de debulha e apresentou menor risco à segurança do operador, atendendo de forma satisfatória às necessidades dos agricultores familiares.

\section{Agradecimentos}

Os autores agradecem à Coordenação de Aperfeiçoamento de Pessoal de Nível Superior (CAPES) e ao Conselho Nacional de Desenvolvimento Científico e Tecnológico (CNPQ) pelo apoio financeiro.

\section{MANUAL CORN THRESHER FOR FAMILY FARMING}

ABSTRACT: The implantation of small agroindustries has been growing among family farmers. Pickled corn is an example of a product sold by these farmers. However, the corn needs to be threshed and this task is usually performed manually using household tools. The current marketed corn threshers are made for large-scale production, and for this reason, family farmers cannot afford one of these machines. Considering the context, this study aimed to develop a corn thresher for smallholders. The methodology used is based on the Phase Model, which is successfully employed in agricultural machinery design and it is divided into four stages: informational design, conceptual design, preliminary design and detailed design. As a result, three conceptions and three models of corn threshers were obtained. After the tests were carried out, the model 3 was determined as the ideal regarding to the family farmers' needs.

Keywords: Agricultural machinery. Product development.

\section{Referências}

[1] IBGE - Instituto Brasileiro de Geografia e estatística. Censo Agropecuário, 2017. Disponível em: https://censos.ibge.gov.br/agro/2017/templates/censo_agro/resultadosagro/agricul tura.html?localidade $=0 \&$ tema $=76510$. Acesso em: $15 / 10 / 2018$.

[2] CONAB, Companhia Nacional de Abastecimento. Acompanhamento da Safra Brasileira - Grãos. Quinto levantamento, Brasília, v. 5, Safra 2017/18 -, p. 1-140, 2018

[3] GARCIA, J. C.; MATTOSO, M. J.; DUARTE, J. O.; Cruz, J. C. Aspectos Econômicos da Produção e Utilização do Milho, Sete Lagoas - MG: Embrapa Milho e Sorgo, 2006. 12p. Disponível em: https://www.infoteca.cnptia.embrapa.br/bitstream/doc/474206/1/Circ74.pdf. Acesso em: 09/10/2018.

[4] MARCOS, S. K.; HONÓRIO, S. L.; JORGE, J. T.; Influência do Resfriamento do ambiente de armazenamento e da embalagem sobre o comportamento póscolheita do milho verde, Revista Brasileira de Engenharia Agrícola e Ambiental, Vol.3, n.1, p. 41-44, 1999.

[5] CRUZ, J. C.; KONZEN, E.A.; FILHO, I. A. P.; MARRIEL, I. E.; CRUZ, E.; DUARTE, J. O.; OLIVEIRA, M. F.; ALVARENGA, R. C. Produção de milho orgânico na agricultura Familiar. Sete Lagoas: Embrapa-CNPMS, 17p. (EmbrapaCNPMS, Comunicado Técnico, 81), 2006.

[6] MATOS, M. J. L. F.; TAVARES, S.A.; SANTOS, F. F.; MELO, M. F.; LANA, M. M. Milho verde. EMBRAPA Hortaliças, 2007. Disponível em: <http://www.cnph.embrapa.br/laborato/pos_colheita/dicas/milho_verde.htm>. Acesso em: 05/11//2018.

[7] CANIATO, F. F.; GAlVÃO, J. C. C.; FINGER, F. L.; RIBEIRO, R. A.; MIRANDA, G. V. PUIATTI, M. Composição de açucares solúveis totais, açucares redutores e amido nos grãos verdes de cultivares de milho na colheita, Revista Brasileira de Milho e Sorgo, v.3, n.1, p. 38-44, 2004.

[8] LUENGO, R. F. A.; CALBO, A. G. Armazenamento de hortaliças. Brasília, Embrapa Hortaliças, 242p, 2001.

[9] PAIVA JUNIOR, M. C. Desempenho de diferentes cultivares para milho verde em diferentes épocas e densidade de semeadura. 1990. 66 f. Dissertação, (Mestrado) - Universidade Federal de Lavras, Minas Gerais. 
[10] PARENTONI, S. N.; GAMA, E. E. G.; MAGNAVACA, R.; REIFSCHNEIDER, F. B.; BOAS, G. Milho doce. Informe Agropecuário, Belo Horizonte, v. 14, n. 165, p. 17 - 22, 1990

[11] NIEMCZEWSKI, B. K.; REIS, A. V. Dos; MACHADO, R. L. T.; MACHADO, A. L. T. Validação de um modelo de cálculo por elementos finitos do chassi de uma semeadora de quatro linhas. Engenharia Agrícola, Jaboticabal, v. 34, n. 1, p. 161-170, fev. 2014.

[12] TEIXEIRA, S. S.; MACHADO, A. L. T; REIS, A. V. Dos; OLDONI, A. Caracterização da produção agroecológica do sul do Rio Grande do Sul e sua relação com a mecanização agrícola. Engenharia Agrícola, Jaboticabal, v.29, n.1, p.162-171, 2009.

[13] STEFANELLO, G.; REIS, A. V. dos; MACHADO, A. L. T.; MACHADO, R. L. T.; MORAIS, C. S. de. Estrutura funcional de uma semeadora de tração humana. Ciência Rural, v.44, n.9, p.1583-1588, set, 2014. Disponível em <http://www.scielo.br/scielo.php?script=sci_arttext\&pid=S010384782014000901583>. Acesso em: 24/06/2019.

[14] CUSTÓDIO, T. V.; SPAGNOLO, R. T.; OLDONI, A.; REIS, Â. V. dos; MACHADO, A. L. T. Estrutura funcional de um encanteirador e depositor de fertilizantes para tratores de baixa potência. Revista Engenharia na Agricultura, v. 26 , n. 2, p. $133-139,2018$

[15] SPAGNOLO, R. T.; OLDONI, A.; CUSTÓDIO, T. V.; MACHADO, A. L. T.; REIS Â. V. dos. Design specifications of a heat applicator weed controller device for family farms. Ciência Rural, Santa Maria, v.48: n. 2, e20170243, 2018.

[16] SPAGNOLO, R. T.; OLDONI, A.; CUSTÓDIO, T. V.; MACHADO, A. L. T.; REIS Â. V. dos. Conceptual design of a thermal weed control machine. Ciência Rural, Santa Maria, v. 49, n. 3, e20180673, 2019

[17] REIS, A. V. Desenvolvimento de concepções para a dosagem e deposição de precisão para sementes miúdas. 2003. 277f. Tese (Doutorado em Engenharia Mecânica) - Universidade Federal de Santa Catarina, Florianópolis, SC.

[18] PAHL, Gerhard; BEITZ, Wolfgang; FELDHUSEN, Jörg; GROTE, KarlHeinrich. Projeto na engenharia: fundamentos do desenvolvimento eficaz de produtos, métodos e aplicações. São Paulo: Edgard Blucher, 2005. 411 p.

[19] ROZENFELD, Henrique; FORCELLINI, Fernando Antônio; AMARAL, Daniel Capaldo; TOLEDO, José Carlos De; SILVA, Sergio Luis Da; ALLIPRANDINI, Dário Henrique; SCALICE, Régis Kovacs. Gestão de desenvolvimento de produtos: uma referência para a melhoria do processo. São Paulo, SP. Saraiva, 2006.542 p.

[20] OLDONI, A. Colhedora-beneficiadora de cebolas para a agricultura familiar: Projeto informacional e conceitual. 2012. 108f. Dissertação (Mestrado em Agronomia). Universidade Federal de Pelotas, Pelotas, RS.

[21] ANVISA. Resolução - RDC n ${ }^{\circ}$ 216/2004. Brasília, 3a Edição. Disponível em: $<$ http://portal.anvisa.gov.br/documents/33916/388704/RESOLU\%25C3\%2587\%2 $5 \mathrm{C} 3 \% 2583 \mathrm{O}$

RDC\%2BN\%2B216\%2BDE\%2B15\%2BDE\%2BSETEMBRO\%2BDE\%2B2004. pdf/23701496-925d-4d4d-99aa-9d479b316c4b>. Acesso em: 07/11/2018.
[22] STEFANELLO, G.; MACHADO, A. L. T.; REIS Â. V. dos.; MACHADO, R. L. T.; Morais, C. S. de. Design specifications of a human-powered planter. Ciência Rural, v.46, n.12, p.2118-2121, dez, 2016.

[23] STEFANELLO, G.; MACHADO, A. L. T.; REIS Â. V. dos.; MORAIS, C. S. de.; OLDONI, A. Design requirements of a human-powered planter. Ciência Rural, Santa Maria, v.47: 06, e20160743, 2017.

[24] Brasil. Mistério da Agricultura, Pecuária e Abastecimento. Instrução Normativa ${ }^{\circ}{ }^{60}$, de 22 de dezembro de 2011. Regulamento Técnico do Milho. Diário Oficial da União. 23.12.2011, Brasília, DF.

[25] GUTIERREZ, J. C. H.; RUBIO, J. C. C.; FARIA, P. E. de.; DAVIM, J. P. Usinabilidade de materiais compósitos poliméricos para aplicações automotivas. Polímeros, São Carlos, v. 24, n. 6, p. 711-719, Dec. 2014.

[26] SILVA, L. C. Substituição do Alumínio pelo Compósito de Poliamida no Suporte do Coxim do Motor. 2014. 109f. Dissertação (Mestrado em Engenharia dos Materiais) - Universidade de São Paulo, São Paulo, SP. 